\section{Endurance in sport}

R. J. Shephard and P.-O. Astrand Oxford, UK: Blackwell Scientific Publications, 1992: 638pp, £39.50, ISBN 0632030356

This volume is another comprehensive and authoritative publication for the Encyclopaedia of Sports Medicine, the result of collaboration between the IOC Medical Commission and the International Federation of Sports Medicine. The editors present a well organized total of 57 contributions, grouped into seven different sections, covering many aspects of aerobic endurance and its application to sport. The first section contains semantic and physiological definitions and notes that the lengths both of competition and of training determine whether an event can be classified as 'endurance'. The second section, entitled 'General Scientific Considerations' consists of

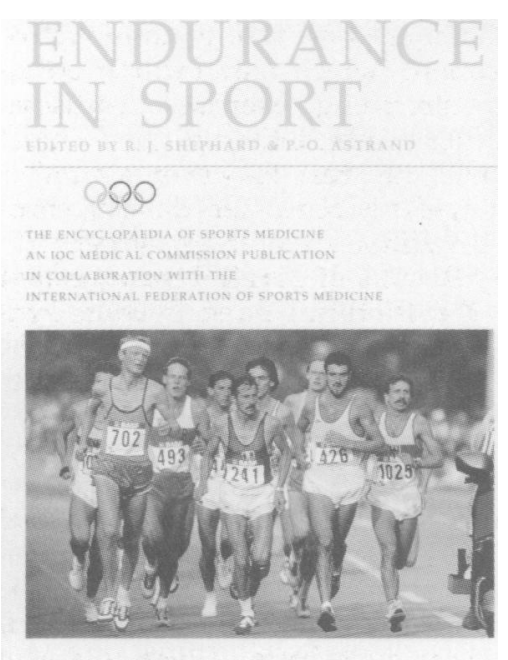

15 contributions on a variety of endurance-related topics, such as cellular metabolism, and cardiovascular and pulmonary functions, together with aspects of psychology as well as genetic determinants of endurance. The third section contains ten papers under the general title 'Measurements of Endurance'. This forms an excellent example of the multidisciplinary approach to assessing and monitoring endurance in man. Sections four and five are composed of ten contributions which discuss principles of diet, psychology, overtraining, and prevention of injuries in endurance athletes, together with endurance training in specific populations such as children and pregnant women. The ten articles of Section six examine clinical aspects of endurance training including problems of high altitude, effects of endurance exercise on the immune response, and cardiac problems in endur- ance sports. The final section, also with ten articles, is entitled 'Specific Issues in Individual Sports'. In this section, swimming, canoeing, cycling, rowing and other sports are discussed physiologically and, in some cases, training advice is provided. As a whole, this book will prove most valuable to sports scientists and their students, to sports doctors, and also to coaches and the more enthusiastic and knowledgeable competitors. Finally, each of the sections is preceeded by reproductions of athletic figures from Greek vases, wearing anachronistic and historically inaccurate swimmingtype briefs. For the most part, the Greek athletes competed naked!

\section{Y. Koutedakis MA, PhD}

\section{Clinical Sports Medicine}

W. A. Grana and A. Kalenak, eds. 527 pp, illustrated. 1991. Philadelphia, USA: W. B. Saunders. $£ 39.50$

The stated aim of this text is to produce a comprehensive textbook valued as a reference for both clinicians and scientists at all levels of expertise - not an easy task. The editors are both orthopaedic surgeons, but have included a wide range of disciplines covered by the 50 authors. The 527 pages are divided into five parts: sports science, general medical problems, rehabilitation of injury, orthotic management and sports injuries.

Sports science is covered in just 77 pages, with chapters on exercise physiology, metabolism, nutrition and exercise testing. Surprisingly, also included is the female athlete and psychology. The chapter on exercise testing and prescription is worth reading but generally the material presented is fairly superficial. Given that the detailed descriptions of the Krebs cycle and ATP production in the metabolism chapter seem out of place.

General medical problems also include an extensive injuries section. There is a useful comprehensive description of on-field management of injuries, and more on the female athlete and psychology.

The section on rehabilitation of injury, gives good practical advice for the sports physician. However, no references are given to back up claims for the effectiveness of therapeutic modalities, and the authors do not appear to have read the work of Mary Dyson.

I would have liked greater detail from the section dealing with orthotic management of injury, particularly with regard to knee orthoses and foot problems.

The largest part of the book is devoted to sports injuries. Special sections are devoted to running, children and the disabled. The regions are reasonably well attended to. There are plenty of black-and-white illustrations and radiographs.

I do not think that Clinical Sports Medicine can be described as comprehensive. The book is largely devoted to injuries, despite hiding head, ophthalmic, face and neck injuries in the general medical problems section! The sports science is rather lightweight, while overtraining, travel and drugs are not mentioned at all. The book has some good parts, and may be useful for a doctor preparing for a diploma, but for reference it would be better to look elsewhere.

\section{R. G. Hackney, FRCS, Dip Sports Med}

\section{The Academy Papers - New} Possibilities, New Paradigms

American Academy of Physical Education Papers No 24

J. Park and H. M. Eckert. Champaign, Illinois: Human Kinetics, 1991: 168 pp

The American Academy of Physical Education publishes a volume of collected papers every year, sometimes a general collection as here, sometimes on specific topics such as Physical Activity and Ageing (Vol 22), or Exercise and Health (Vol 17). This collection of 19 papers is of only peripheral interest to most BASM members unless they have a specific interest in physical education, as this volume is primarily concerned with the education debate within the profession. However, there are some contributions of general interest, for example R. K. Dishman on 'The failure of sport psychology in the exercise and sports sciences' - not exactly a title one might have expected to find coming from America! 'An ecological approach to training' by physiologist Christine Wells and M. Gilman, 'Mechanisms for making an interdisciplinary doctoral programme in exercise science work' by D. M. Landers, and 'Studying human movement' by J. $R$. Thomas are stimulating and interesting topics in the context of BASM readership.

For most of us, this would not be a book to buy, but it could well be one to look into, especially for those of us in education.

\section{Craig Sharp PhD, MRCVS}

